Sección dos: Textos

Educación y Exclusión social

\title{
Educación Emocional y Exclusión social ${ }^{1}$
}

Emotional Education and Social Exclusion

José Antonio Ayuso Marente

Facultad Ciencias de la

Educación

Teoría e Historia de la

Educación

joseantonio.ayuso@uca.es

\section{Resumen}

Resumen: El presente artículo es una aproximación al mundo de las emociones, sentimientos y valores en la sociedad actual. En un mundo donde la resiliencia ocupa un papel fundamental se plantea la importancia de una buena educación emocional para que nuestros jóvenes tengan una adecuado crecimiento y desarrollo personal que les permita integrarse de manera crítica en el mundo que les ha tocado vivir.

Palabras Clave: educación, valores, sociedad, inteligencia emocional

\begin{abstract}
This article is an approximation to the world of emotions, feelings and values in today's society. In a world where resilience plays a fundamental role, the importance of a good emotional education is raised so that our young people have an adequate growth and personal development that allows them to integrate critically in the world that they have to live.
\end{abstract}

Keywords: Education, values, society, emotional intelligence

${ }^{1}$ Recibido:10/06/2018 Evaluado: 28/06/2018 Aceptado: 10/07/2018 


\section{Educación emocional}

Existe un consenso generalizado desde hace mucho tiempo y en diferentes contextos (laboral, educativo, social, etc.) sobre la importancia que tiene el manejo exitoso de nuestras emociones por encima de nuestro cociente intelectual o experiencia profesional.

Cada vez se valora más la manera que tenemos de relacionarnos con nosotros mismos y con los demás que nuestros estudios académicos.

Sin embargo, es curioso, que, a pesar de este consenso generalizado sobre la necesidad de formar personas emocionalmente competentes, sigamos en nuestro sistema educativo, primando prácticas que inciden casi exclusivamente en habilidades "académicas" desplazando, si no desechando, las personales.

En la sociedad actual nos encontramos con que el éxito es cada vez más volátil, difícil, efímero. Conocida es la definición de modernidad líquida que nos propone el sociólogo Zygmunt Bauman (2002) en donde todo parece frágil, incierto y el desconcierto inunda en gran medida a las sociedades occidentales. De ahí el riesgo de que nuestros jóvenes puedan quedar excluidos de la sociedad. Muchas veces como una opción de protesta voluntaria ante el desafío de una sociedad cambiante, insegura e inhóspita que, en gran medida, les llena de miedo y ansiedad. El riesgo de quedarse al margen y no participar en sociedad puede abrir caminos sustitutivos como las relaciones o vidas virtuales, las conductas violentas de bandas, alcohol, depresión, etc. Ante este panorama parece necesario que las personas podamos desde una edad temprana acceder a una adecuada educación emocional que nos ayude a conocer, interpretar y manejar nuestras emociones ya que todas son necesarias e imprescindibles para nuestra vida en sociedad.

Antes esta realidad social Monika Grhul (2009) nos habla de una fuerza fundamental en la vida; la resiliencia. Es decir, la capacidad de adaptación y superación por parte de los seres humanos de ciertas crisis en nuestro ciclo vital gracias a recursos personales y sociales. Esta elasticidad o capacidad de resistencia ante los problemas se conseguiría con la adquisición de una serie de actitudes fundamentales (Optimismo, aceptación y orientación a la búsqueda de soluciones) y cuatro capacidades (Autorregulación, asunción de responsabilidades, estructurar las relaciones y configurar el futuro). Evidentemente, la autorregulación, estaría directamente relacionada con la automotivación, la autodisciplina, el afrontamiento del estrés, es decir con nuestra inteligencia emocional, el manejo de nuestras emociones.

Pero ¿qué son las emociones? siguiendo a Bisquerra (2003) hablaríamos de un estado complejo del organismo caracterizado por una excitación o perturbación que predispone a una respuesta organizada. Las emociones se generan según este autor como respuesta a un acontecimiento externo o interno, siguiendo el siguiente esquema: unas informaciones sensoriales llegan a los centros emocionales del cerebro, como consecuencia se produce una respuesta neurofisiológica y el neocortex interpreta la información. 
El interés sobre las emociones es relativamente reciente, a finales del siglo pasado Salovey y Mayer (1990) crean el termino inteligencia emocional definiéndola como las habilidades para gestionar sentimientos y emociones, sabiéndolas caracterizar por separado para desenvolverse eficazmente en la sociedad gracias a este conocimiento.

Por tanto, vemos como parece fundamental la necesidad de saber seleccionar o escoger la emoción adecuada (es decir seleccionar la mejor entre varias posibles) en un contexto concreto y en un momento determinado, pero también con la intensidad oportuna (Aguado, 2014)

Conviene clarificar las diferencias entre emociones, sentimientos y valores. Cuando hablamos de emociones podemos hacer referencia a impulsos que generan reacciones o consecuencias automáticas que constituyen un conjunto innato de sistemas adaptativos al medio (Segura, 2009).

Otros autores hablan de un conjunto complejo de respuestas químicas y neuronales que forman un patrón distintivo (Damásio, 2005). En definitiva parece que las emociones son respuestas necesarias para adaptarnos a nuestro medio y que nos ayudan a sobrevivir en él. Siguiendo a Mar Romera (2017) las emociones son intensas, cortas e internas, parecería como si tuvieran vida propia y serían provocadas por estímulos tanto internos como externos, Además las emociones serían las mismas en todas las familias, en todas las personas del planeta Tierra. los sentimientos serían la parte consciente de la emoción, la traducción cognitiva, condicionada por cultura y valores de la persona y finalmente los valores aparecerían como constructos culturales provenientes de costumbres, creencias y culturas concretas aprendidos y diferentes en cada momento histórico, sociedad o cultura.

Han sido varios los intentos de clasificar las emociones a lo largo de la historia, el psicólogo Paul Ekman (1993) realizó una investigación a principios de los años setenta del siglo pasado en la que implementó un estudio transcultural en la isla de Papúa Nueva Guinea obteniendo como resultado seis emociones universales; alegría, tristeza, ira, miedo, sorpresa y asco. Goleman (1996) distingue las siguientes emociones primarias; ira, tristeza, miedo, alegría, amor, sorpresa, aversión y vergüenza. Bisquerra (2000) distingue entre emociones negativas, positivas, ambiguas y estéticas. Básicamente coincide con las anteriores mencionadas pero añadiendo; ansiedad, humor; esperanza y compasión. Segura y Arcas (2005) nos hablan de la alegría, esperanza, miedo, vergüenza, deseo, envidia, celos, ira, rencor, orgullo y amor. Vemos como son varias las emociones que el ser humano puede llega a sentir y la dificultad de delimitar los umbrales y matices que las emociones presentan.

Hoy en día se está convirtiendo la inteligencia emocional en un tema recurrente. No podemos obviar en el análisis sobre este interés por lo emocional a la cultura que inevitablemente acompaña a cada sujeto en su momento histórico. Muchos niños y jóvenes viven en la actualidad inmersos en lo que se viene denominando la sociedad de la comunicación y la imagen, accediendo sin límites a todo tipo de información sin ninguna barrera gracias a las nuevas tecnologías de la comunicación y de la información. El papel cultural en la escuela hoy es vital. En ella nos jugamos gran parte de la enculturación y desarrollo de su personalidad de nuestros jóvenes. La relevancia del contenido que se aprende, su significado para quiénes lo aprenden, la motivación, sus posibilidades para favorecer capacidades de 
expresión, comunicación, valores, etc. son aspectos fundamentales y decisivos para la formación de una ciudadanía con una competencia social ajustada (Ayuso, 2010).

La aproximación a la definición de las emociones nos lleva, inevitablemente a la inteligencia emocional, ésta según Goleman (1996) nos remite a una capacidad de reconocer nuestros propios sentimientos, los sentimientos de los demás y, en definitiva, motivarnos y manejar adecuadamente las relaciones que sostenemos con los demás y con nosotros mismos.

De alguna manera la inteligencia emocional puede concretarse en determinadas habilidades más concretas y prácticas o también llamadas inteligencias múltiples (Gardner, 2008), dentro de las diversas inteligencias propuestas por el Doctor Howard Gardner quisiéramos centrarnos en la inteligencia intrapersonal y la interpersonal. Este abordaje de lo emocional referido a las inteligencias intra e inter personal nos lleva inevitablemente a considerar cómo incide ésta última en la necesaria integración sociocrítica de un ser humano en su contexto social y procesos de grupo. Necesitamos de una adecuada regulación afectiva que complemente con fluidez y eficacia su relación con los ámbitos cognitivos y motores que desarrollan su personalidad. Este equilibrio nos ayudará a entendernos mejor con nosotros mismos para entender y leer mejor los sentimientos de los demás. Toda persona competente socialmente necesita de una adecuada inteligencia interpersonal que le permita entender a los demás para relacionarse eficazmente con ellas.

\section{Sociedad, cultura y educación}

Evidentemente la influencia de la cultura como contexto condicionante tiene tanta importancia que determinados autores llegan a hablar de culturas con diferentes perfiles emocionales. Es decir, habría componentes que podrían definir si el perfil emocional de la cultura es bajo o alto (Fernández, Zubieta y Páez, 2002). Estos componentes serían los siguientes:

\section{1.- Culturas individualistas y colectivistas.}

2.- Culturas masculinas y femeninas.

3.- Culturas de alta distancia de poder y culturas igualitarias.

4.- Culturas con alta evitación de la incertidumbre y culturas con baja evitación de la incertidumbre.

Por tanto podemos deducir que la manera de expresar ciertas emociones podrían estar fuertemente condicionadas según el contexto cultural, especialmente, si éste es diferente al de origen. Es decir, aunque las emociones como ya decíamos anteriormente son las mismas para todas las personas, la manera de expresarlas podría no serla. Por ejemplo un niño emigrante acogido en un centro podría tener dificultades a la hora de expresarlas si su educador o educadora no conoce la cultura del país de origen. 
Siguiendo a Jiménez (2014), parece fundamental que los profesionales de la educación conozcan las culturas de origen de aquellos jóvenes con los que trabajen. Si queremos que, por ejemplo, los menores migrantes sean competentes en el país receptor parece necesario que el educador conozca la cultura de su país de origen. Este autor define las competencias interculturales como un conjunto de actitudes, habilidades y conocimientos que al ser puestas en marcha movilizan y generan relaciones de inclusión y respeto entre personas de grupos culturales diversos.

Un recurso lúdico y educativo que tenemos los educadores siempre a mano es el juego o los deportes. En definitiva la actividad física es siempre generadora de estímulos que pueden ser utilizados para educar en valores y aprender a gestionar nuestros sentimientos. Partiendo de la necesidad de que nuestros jóvenes participen en deportes respetando las reglas y el juego limpio podríamos trabajar los siguientes contenidos (Castillo, 2015):

1.- Respeto del jugador por el adversario por encima de todo, entendiendo que éste es un compañero y no un enemigo.

2.- Conocimiento y respeto por las reglas del deporte a practicar, junto con el respeto al individuo que favorece a su cumplimiento

3.- Educar para la tolerancia y el dominio de uno mismo, aprendiendo a controlar emociones y sensaciones

4.- Aprender a aceptar la victoria y la derrota

5.- Contribuir al principio de igualdad para todos, sin tener en cuenta las insignificantes diferencias que nos caracterizan a unos y a otros.

6.- El entrenador o docente encargado del proceso deportivo debe ser un modelo a seguir y debe reunir las competencias necesarias para transmitir valores positivos

Sin duda el deporte o el juego son de los mejores recursos lúdico educativos que podemos encontrar. Existe un amplio consenso, por no decir unanimidad en considerar el juego como un elemento de vital importancia para el crecimiento y desarrollo de una infancia y como excelente medio de aprendizaje. Mar Romera (2017) presidenta de la Asociación Pedagógica Francesco Tonucci nos traslada una serie de reflexiones sobre este tema:

- Los aprendizajes más importantes de la vida se hacen jugando. Es necesario explorar en libertad.

- El lugar ideal de juego: la calle sin vigilancia; a los niños y niñas debemos vigilarlos de lejos, sin que ellos lo sepan. La calle es el lugar perfecto para encontrarse con amigos, decidir los juegos, las reglas, ganar, perder, aprender a manejar las propias emociones y sentimientos en el grupo de iguales sin ayuda de los adultos, sin que éstos soluciones los posibles conflictos. 
- Jugar necesita tiempo y espacio, estos es una evidencia, es una cuestión de sentido común, pero son los dos grandes problemas de nuestro momento social:tiempo y espacio.

El deporte y los juegos pueden ayudarnos a trabajar con nuestros jóvenes la gestión de sus sentimientos y la toma de conciencia de sus emociones positivas y negativas. Igualmente el docente transmite valores de manera consciente o inconsciente. En palabras de Barragán Medero (2002) la educación y valores son algo inseparable. Los valores siempre se comunican. Lo importante es discutir cuáles, quién los elige, cómo y si favorecen la autonomía moral. Respectó a qué valores deberíamos transmitir creemos que un mínimo o punto de partida es la llamada ·Ética Universal", es decir los valores y normas básicas establecidas en función de unos principios o criterios universales y de unas actitudes morales básicas que conforman los Derechos Humanos, esto es, valor de la vida, dignidad, justicia, libertad, igualdad o solidaridad.

\section{La educación en valores como base del bienestar emocional}

Como educadores tenemos que hacer posible la transmisión de estos valores, cada uno en el ámbito que le ha tocado estar. Se hace necesario que el profesorado se plantee un determinado Saber Ser (Delors 1996) y trabaje la empatía, asertividad y habilidades sociales que permitan a los jóvenes percibir referentes morales. Siguiendo a Ayuso y Gutiérrez (2007) se deben establecer canales de comunicación en el aula, crear climas de confianza y espacios de acogida (sobre todo si trabajamos con jóvenes migrantes) evitando que las falsas expectativas y los estereotipos limiten nuestro trabajo. Igualmente en la sociedad actual parece del todo necesario que los profesionales aprendamos a trabajar de una manera más flexible, quizá necesitando menos organizaciones grandes e institucionales y más grupos sociales con capacidad multifuncional e interconectados cuya fuerza radique en su capacidad de trabajar en red para conseguir apoyo mutuo.

Pero ¿Cómo se transmiten estos valores? y ¿Qué valores?, respecto a la estas cuestiones Ayuso y Núñez (2010) apuntan que las dificultades pueden ser grandes, pero se deben ensayar algunas respuestas. Debemos aclarar, en primer lugar, que no estamos hablando de que el profesorado tenga que estar obligado a dar clases de Ética o Deontología. Tampoco participamos de la idea que sólo los profesionales de la cuestión, expertos en axiología, sean los únicos legitimados para enseñar o transmitir determinados valores.

Estamos convencidos que el ejemplo y la invitación a la reflexión (sobre todo con dilemas morales) pueden ser los vehículos más adecuados para una auténtica transmisión de valores. Siguiendo a Segura y Arcas (2005) coincidimos en que algunos métodos para enseñar valores, además de los ya señalados como el ejemplo del educador o los dilemas morales, son el diálogo con iguales sobre temas morales, el conocimiento de las grandes religiones y del pensamiento de los grandes hombres y mujeres a lo largo de la Historia. Igualmente la dramatización de determinadas películas o novelas, la clarificación de valores, discusión de noticias de periódicos o televisión, etc.

Este imperativo obedece a la responsabilidad pública que tiene todo educador. Además de transmitir conocimientos debemos ser conscientes de que queramos o no transmitimos una 
forma de ser, una forma de vida. La educación nunca es neutra, la instrucción nunca es aséptica. La educación siempre compromete y provoca emociones y sentimientos. Sin duda la transmisión de saberes teóricos debe ir acompañado de una plena conciencia por parte de los educadores de su capacidad de influir en el crecimiento y desarrollo personal de sus educandos. No debemos olvidar el rol del educador ante retos tan importantes como los aprendizajes que ayudan a mejorar la convivencia, a respetar la diversidad, a relacionarnos con iguales, aprender a perder y aprender a ganar, en definitiva, nuestra influencia en la formación del carácter y la conciencia moral de nuestros jóvenes.

Una de las competencias del profesorado es la de enseñar en valores, en palabras de Ayuso (2010)

"El profesorado no debe olvidar que es inevitable la integración de una dimensión moral en la formación escolar. No formamos sólo buenos estudiantes, sino buenos ciudadanos que deberán actuar de forma responsable, libre y comprometida. Este planteamiento exige un nuevo rol pedagógico en el profesorado del siglo XXI. Por un lado, gestor de procesos de enseñanzaaprendizaje $\mathrm{y}$, por otro, modelo de actuación y de guía en el tratamiento de dilemas éticos propios de su área de conocimiento o relativos a temas socialmente controvertidos vinculados con la ciudadanía"

Cuando una persona adulta llegar a una situación de exclusión social debemos considerar que no siempre se llega a ese punto de su ciclo vital de una manera sorpresiva o inesperada. Es mucho antes cuando se producen determinadas condiciones personales, familiares y sociales que van determinando, en gran medida, el rumbo que va tomando una vida. De ahí la importancia de un adecuado entorno emocional que ayude a lograr un equilibrio en el crecimiento y desarrollo personal de todo ser humano. La familia como primer lugar de aprendizaje, incluido el vientre materno, es el inicio de nuestra búsqueda de la felicidad y por tanto del manejo de las emociones y sentimientos propios y ajenos. Poco a poco iremos aprendiendo a tomar conciencia y prestar atención del universo emocional que nos rodea y a reconocer nuestros pensamientos asociados a este universo.

Este aprendizaje es fundamental que se realice, para ello los centros educativos o instituciones públicas de atención a jóvenes deben trabajar en paralelo con las familias o intentar, en algunas ocasiones, compensar los déficits que en ella pudieran generarse.

El objetivo es ayudar a nuestros jóvenes a que sean fuertes emocionalmente para que sepan enfrentar las dificultades y sepan elegir entre las múltiples situaciones que encontrarán a lo largo de su vida. hay que preparar a nuestros jóvenes para que den vida a los años y no años a la vida. Quizás más que prepararlos para que sean felices el objetivo más realista, aunque nadie dijo que fuera fácil, sería prepararlos para que disfruten de los momentos buenos y sepan levantarse ante los problemas que sin duda llegarán, disfrutar del momento presente y cultivar la plena conciencia del aquí y ahora pero aprendiendo del pasado y previendo algunas estrategias para su futuro, que intenten ser amables, corteses y honestos.

Cuántos problemas o situaciones complicadas podrán resolver si adquieren la disciplina y generosidad de dar las gracias o pedir perdón. La familia es clave para que la vida de nuestros 
jóvenes sea de satisfacción y plenitud, grandes fortalezas de todo ser humano como la gratitud, la capacidad de amar y ser amado, la curiosidad o el optimismo tienen su base en la familia. Nuestra responsabilidad como educador será la de remar en esa dirección, con la familia y con la sociedad o, simplemente, solos. El resultado, es evidente que no puede depender de nosotros, pero siempre tendremos la satisfacción de haber actuado como debíamos.

Muchos problemas relacionados con la falta de competencia social tienen su antecedente en un insuficiente conocimiento y por tanto gestión de nuestros sentimientos. Las emociones no podemos evitarlas, es más, son necesarias para nuestra supervivencia como especie.

Son adaptativas y no tiene mucho sentido catalogarlas de buenas o malas. Ya hemos visto que son impulsos, comportan reacciones automáticas, son internas, intensas, cortas y parece como si tuvieran vida propia. Sencillamente no podemos evitarlas. Nuestro cuerpo reacciona de manera fisiológica frente a estímulos internos o externos con carga emocional.

Pero otra cosa son los sentimientos, es decir, la representación mental del estado fisiológico y sensorial de mi cuerpo. Estos son la parte consciente de la emoción y están mediatizados por la realizad que nos rodea, nuestros valores, deseos y proyectos propios. Son el arraigo de una emoción desde la traducción cognitiva condicionada por la cultura y la estructura axiológica de cada persona (Romera, 2017)

Si queremos que nuestros jóvenes tengan una adecuada integración socio-crítica en cada contexto social que les toque vivir no debemos minusvalorar el mundo de las emociones y sentimientos. Lo importante es que sean capaces de desarrollarse como personas íntegras, honestas, valientes, comprometidas, etc. pero no sólo "sabiendo lo que hay que hacer" sino ayudándoles a que de manera cada vez más consciente y autónoma "puedan hacerlo" .

Si conseguimos una buena alfabetización emocional entre nuestros chicos y chicas es más probable conseguir una sociedad más integradora, más inclusiva y por tanto más abierta a la diversidad y más eficiente para asumir los retos de la postmodernidad.

\section{Referencias}

Aguado, R. (2014). Es emocionante saber emocionarse. Madrid: EOS.

Ayuso, J.A. (2010). Las competencias básicas en educación: un nuevo reto cultural para la ciudadanía. En V. Amar Rodríguez (Ed.), Educación, ideología, cultura y contextos. (pp. 319-335). Cádiz: Servicio Publicaciones Universidad de Cádiz.

Ayuso, J.A. y Gutiérrez, C. (2007). Educación en valores y profesorado. Revista Educación en Valores (Universidad Carabobo, Venezuela), Vol.1, nº 7, 108-118

Ayuso, J.A y Núñez, M.A. (2010). Educación en valores, liderazgo y éxito profesional docente. Revista Clave XXI Reflexiones y Experiencias en Educación, CEP Villamartín, Vol. 1, $n^{\circ} 3$. 
Bauman, Z. (2002). Modernidad líquida. México: Fondo de Cultura Económica

Bisquerra, R. (2000). Educación emocional y bienestar. Barcelona: Praxis.

Bisquerra, R. (2003). Educación emocional y competencias básicas para la vida. Revista de Investigación Educativa, Vol. 21, n. ${ }^{\circ}$, págs. 7-43

Castillo,I., Ramis, y., Cruz, J. y Balaguer, I. (2015).Formación de entrenadores de fútbol base en el proyecto PAPA. En revista de Psicología del Deporte, 24(1), 131-138

Fernández, I., Zubieta, E., y Páez, D.(2001). Emocionarse en Latinoamérica. International Journal of Social Sciences and Humnanities (Sociotam), XI (1), 29-53

Jiménez, A.S. (Coord.) (2014). Infancia, cultura y emoción. Granada: GEU

Gardner, H. (2008). Inteligencias múltiples. La teoría en la práctica. Barcelona: Paidós

Goleman, D. (1996). Inteligencia Emocional. Barcelona: Kairós

Goleman, D. (1999). La Práctica de la Inteligencia Emocional. Barcelona: Kairós

Romera, M. (2017). La familia, la primera escuela de las emociones. Barcelona: Destino.

Segura, M. y Arcas, M. (2005). Educar las emociones y los sentimientos. Madrid: Narcea

Segura, M. (2007). Ser persona y relacionarse. Madrid: Narcea 